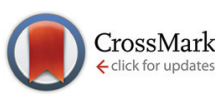

Cite this: Dalton Trans., 2016, 45, 618

\section{Water based scale-up of CPO-27 synthesis for nitric oxide delivery $\dagger$}

\author{
Damiano Cattaneo, ${ }^{a}$ Stewart J. Warrender, ${ }^{* a}$ Morven J. Duncan, ${ }^{a}$ \\ Richard Castledine, ${ }^{b}$ Nigel Parkinson, ${ }^{b}$ Ian Haley ${ }^{\mathrm{c}}$ and Russell E. Morris ${ }^{\mathrm{a}}$
}

Received 9th October 2015,

Accepted 11th November 2015

DOI: $10.1039 / \mathrm{c} 5 \mathrm{dt} 03955 \mathrm{j}$

www.rsc.org/dalton
The applicability of water-based reflux and room temperature synthesis processes for the production of CPO-27 MOFs, suitable for NO delivery applications, is investigated. NO adsorption, storage and release performance of products obtained under reflux conditions are comparable to those of equivalent samples synthesised from traditional solvothermal methods at small scale. Products obtained from room temperature processes show lower NO release capability, although the quantities that are released are still more than adequate for biomedical applications. Results also reveal differences for the first time in NO uptake, storage and release depending on whether $\mathrm{Zn}, \mathrm{Ni}$ or $\mathrm{Mg}$ is employed. The results indicate that while the crystallinity of $\mathrm{CPO}-27(\mathrm{Zn})$ and $\mathrm{CPO}-27(\mathrm{Mg})$ is not affected by moving to lower temperature methods, the crystallinity of $\mathrm{CPO}-27(\mathrm{Ni})$ is reduced. Particle morphology and size is also affected. The low temperature processes are successfully demonstrated at $20 \mathrm{~L}$ and $100 \mathrm{~L}$ scale and the main problems encountered during scale-up are outlined. The $100 \mathrm{~L}$ scale is in itself an appropriate production scale for some niche biomedical products. Indeed, results indicate that this synthesis approach is suitable for commercial production of MOFs for this application field. We also confirm that BET surface area from nitrogen adsorption at $77 \mathrm{~K}$ is not a good indicator for successful adsorption of $\mathrm{NO}$.

\section{Introduction}

Metal organic frameworks (MOFs) are some of the most important recent developments in materials science. ${ }^{1,2}$ They are nanoporous solids, formed by connecting metals with organic linking groups into extended networks. Their huge porosity and accessible surface area makes them ideal for gas storage and delivery uses, with potential applications across a wide range of fields - including hydrogen storage for energy, ${ }^{3} \mathrm{CO}_{2}$ capture in industry ${ }^{4}$ and chemical separations. ${ }^{5}$ Recently, we have shown that they can also be used for the storage/delivery of bio-active gases such as nitric oxide (NO), with exceptional behaviour over the whole adsorption-storage-delivery cycle. ${ }^{6}$

$\mathrm{NO}$ is an important messenger molecule in our body; it controls blood platelet adhesion, blood pressure and cell proliferation. ${ }^{7}$ This colourless free radical gas has been studied for in vitro and in vivo antibacterial, wound healing and antithrombotic applications, ${ }^{8,9}$ for which the ability to deliver precise and controlled doses is highly desirable. We are there-

\footnotetext{
${ }^{a}$ School of Chemistry, University of St Andrews, North Haugh, St Andrews KY16 9ST, UK.E-mail: sjw9@st-andrews.ac.uk

${ }^{b}$ Fine Industries Ltd, Seal Sands, Middlesbrough, TS2 1UB, UK

${ }^{c}$ Mettler-Toledo Ltd, 64 Boston Rd, Beaumont Leys, Leicester, LE4 1AW, UK

$\dagger$ Electronic supplementary information (ESI) available. See DOI: 10.1039/ c5dt03955j
}

fore interested in developing MOFs for use in biological and biomedical applications firstly because of their ability to release safe yet biologically active levels of NO, and secondly because of their potential to help deliver the gas exactly where and when it is required. The biologically active amount of nitric oxide required depends on the targeted application. For example, anti-thrombosis applications require only very small amounts (pmol s ${ }^{-1} \mathrm{~cm}^{-2}$ flux), ${ }^{9}$ while antibacterial applications may require an order of magnitude more flux.

$\mathrm{CPO}-27(\mathrm{Ni})$ has shown great promise as an NO delivery agent. ${ }^{6}$ Due to its porous nature and coordinatively unsaturated metal sites (CUS), this material exhibits high capacity and stable storage coupled with controllable and reversible release. Traditional procedures for the synthesis of CPO-27(Ni) and its compositional analogues (including CPO-27( $\mathrm{Mg})$ and CPO-27(Zn)) are based on solvothermal methods employing solvents such as dimethylformamide and tetrahydrofuran, at high temperatures over extended time periods (up to 3 days). Table 1 summarises typical conditions used in these solvothermal preparations. Lower temperature procedures have been developed, but still with a dependence on organic solvents such as dimethylformamide. ${ }^{10}$

In order to permit storage of gases and other guest species, solvent molecules must be removed from the MOF in a process known as activation. This process, which renders the high surface area and pore volume accessible, and generates CUSs, 
Table 1 Summary of reaction conditions, solvent exchange methods, activation procedures and resulting BET surface areas reported in the literature for CPO-27(Ni), (Mg), and ( $\mathrm{Zn})$

\begin{tabular}{|c|c|c|c|c|c|c|}
\hline Metal & Solvents & $\begin{array}{l}\text { Reaction temperature } \\
\text { and duration }\end{array}$ & $\begin{array}{l}\text { Solvent exchange } \\
\text { method }\end{array}$ & $\begin{array}{l}\text { Activation } \\
\text { conditions }\end{array}$ & $\begin{array}{l}\mathrm{N}_{2} \text { adsorption } \\
77 \mathrm{~K}\left(\mathrm{~m}^{2} \mathrm{~g}^{-1}\right)\end{array}$ & Ref. \\
\hline $\mathrm{Ni}$ & DMF/ethanol/ $\mathrm{H}_{2} \mathrm{O}$ & $373 \mathrm{~K} / 24 \mathrm{~h}$ & $\mathrm{MeOH}(2$ days $\times 4)$ & $523 \mathrm{~K} 5 \mathrm{~h}$ & 1070 & 11 \\
\hline \multirow[t]{2}{*}{$\mathrm{Mg}$} & DMF/ethanol/ $\mathrm{H}_{2} \mathrm{O}$ & $398 \mathrm{~K} / 20 \mathrm{~h}$ & $\mathrm{MeOH}(2$ days $\times 4)$ & $523 \mathrm{~K} 5 \mathrm{~h}$ & 1495 & 11 \\
\hline & $N$-Methylpyrrolidone $/ \mathrm{H}_{2} \mathrm{O}$ & $393 \mathrm{~K} / 24 \mathrm{~h}$ & $\mathrm{MeOH}(7$ days $\times 7)$ & $\begin{array}{l}513 \mathrm{~K} 48 \mathrm{~h} \\
393 \mathrm{~K} 1 \mathrm{~h}\end{array}$ & 1542 & 12 \\
\hline \multirow[t]{3}{*}{$\mathrm{Zn}$} & DMF/propanol/ $\mathrm{H}_{2} \mathrm{O}$ & $373 \mathrm{~K} / 20 \mathrm{~h}$ & $\mathrm{MeOH}(2$ days $\times 2)$ & $543 \mathrm{~K} 16 \mathrm{~h}$ & 816 & 15 \\
\hline & $\mathrm{DMF} / \mathrm{H}_{2} \mathrm{O}$ & $373 \mathrm{~K} / 20 \mathrm{~h}$ & $\mathrm{MeOH}(6$ days $\times 3)$ & $543 \mathrm{~K}$ & 783 & 16 \\
\hline & $\mathrm{THF} / \mathrm{NaOH} / \mathrm{H}_{2} \mathrm{O}$ & $383 \mathrm{~K} / 3$ days & $a$ & & $a$ & 17 \\
\hline
\end{tabular}

${ }^{a}$ Not reported.

is typically achieved through heat treatment. However, the pores of products from traditional synthesis methods can be occupied by solvent molecules that cannot be easily removed by this method. Furthermore, some solvents form very strong adducts with metal sites within the framework making it difficult to create CUSs by heating at temperatures below the thermal decomposition of the MOF. In these circumstances solvent exchange processes are required to introduce lower boiling and less strongly coordinating solvent molecules to permit activation at lower temperatures. ${ }^{11,12,18}$ For example, the MOFs prepared by Caskey et al. (see Table 1) are synthesised in DMF and are then solvent exchanged four times over two days in methanol to attain high gas adsorption capacities. $^{11}$ Similarly, magnesium CPO-27 MOF prepared using a mixture of THF and water requires solvent exchange in methanol over numerous days. ${ }^{14}$ Currently the only structure reported that does not require solvent exchange is CPO-27(Ni) prepared using a mixture of THF and water. ${ }^{12,13}$ It is noted that the activation conditions for each material reported in Table 1 involve temperatures (after solvent exchange) higher than $473 \mathrm{~K}$, under dynamic vacuum.

It is evident from these representative examples that traditional synthesis procedures for these potentially industrially important materials are not particularly environmentally friendly or favourable for larger scale production, given the length of time involved, multiple steps, harmful solvents and high temperature (energy) requirements.

In recent years, we and other groups have shown that CPO-27(Zn) and (Ni) can be obtained from simple water-based reactions operated at room temperature or under reflux. ${ }^{19-21}$ The development that enabled the move away from organic solvents was the conversion of the organic linker (in this case dihydroxyterephthalic acid) from its protonated (and water insoluble) form to its $\mathrm{Na}$ salt - either by first isolating the salt prior to use in the MOF synthesis ${ }^{19}$ or in a single step process in which the linker is dissolved in aqueous $\mathrm{NaOH}^{19-21}$ and used as a solution (but without the additional use of organic solvents employed in previous literature reported methods ${ }^{14}$ ).
It has been claimed that this move away from solvothermal processes will facilitate the larger scale production of MOFs due to the simplicity of the reaction and required equipment, as well as the more environmentally friendly and less energy intensive nature of the new process. We also speculate that the use of a water-rich synthesis medium will generate products that do not require solvent exchange prior to activation in order to permit gas adsorption and storage.

In this contribution, we investigate the applicability of this approach in producing CPO-27 MOFs for NO storage and release - namely $\mathrm{CPO}-27(\mathrm{Zn}),(\mathrm{Ni})$ and $(\mathrm{Mg})$, and compare for the first time the NO adsorption, storage and delivery performance of these three isotypes. We also show that such methods do indeed lend themselves well to larger scale production and herein report the development process undertaken to enable scaling up of the method to $20 \mathrm{~L}$ and $100 \mathrm{~L}$ scales.

Throughout the following text, products are identified and named based on their synthesis method using the following nomenclature - Solv $=$ prepared solvothermally, $\mathrm{RF}=$ prepared under reflux, $\mathrm{RT}=$ prepared at room temperature, $2 \mathrm{~S}=$ prepared in a two-step process, $1 \mathrm{~S}=$ prepared in a one step process. For example, $2 \mathrm{SRF}=$ material prepared under reflux conditions using a two-step procedure.

\section{Experimental section}

\section{Synthesis procedures}

All reagents and solvents employed were commercially available, high-grade purity materials (Aldrich or Fluka) which were used without further purification.

\section{Solvothermal method}

$\mathrm{Mg}_{2}(\mathrm{dhtp})\left(\mathrm{H}_{2} \mathrm{O}\right)_{2} \cdot 8 \mathrm{H}_{2} \mathrm{O} \mathrm{Solv}-\mathrm{CPO}-27(\mathrm{Mg}), \mathrm{Zn}_{2}(\mathrm{dhtp})\left(\mathrm{H}_{2} \mathrm{O}\right)_{2} \cdot 8 \mathrm{H}_{2} \mathrm{O}$ Solv-CPO-27(Zn) and $\mathrm{Ni}_{2}($ dhtp $)\left(\mathrm{H}_{2} \mathrm{O}\right)_{2} \cdot 8 \mathrm{H}_{2} \mathrm{O} \quad \mathrm{Solv}-\mathrm{CPO}-27(\mathrm{Ni})$ were prepared according to published procedures ${ }^{12-14,17}$ using a mixture of THF, sodium hydroxide and water. The $\mathrm{Mg}$ and $\mathrm{Zn}$ products were solvent exchanged as per the procedures but, 
as discussed earlier, it is not necessary to solvent exchange the Ni-based product.

Two-step method under reflux and at room temperature

This method involves preparing and isolating the sodium salt of the linker as a solid powder prior to its use in the MOF synthesis. Sodium 2,5-dihydroxyterephthalic acid, $\left[\mathrm{Na}_{2}(\mathrm{dhtp}) \cdot 2 \mathrm{H}_{2} \mathrm{O}\right]$ was prepared following the reported method, ${ }^{19}$ whereby 2,5-dihydroxyterephthalic acid (dhtp) (10 g, $5.05 \times 10^{-2} \mathrm{~mol}$ ) was dissolved in a $400 \mathrm{~mL}$ solution of $\mathrm{NaOH}$ $\left(8.08 \mathrm{~g}, 2.02 \times 10^{-1} \mathrm{~mol}\right)$ in water and ethanol $(1: 1)$. The mixture was rotary evaporated and the resulting solid product was refluxed for 4 hours in ethanol before being filtered and dried in air overnight (93\% yield).

$\mathrm{Mg}_{2}($ dhtp $)\left(\mathrm{H}_{2} \mathrm{O}\right)_{2} \cdot 8 \mathrm{H}_{2} \mathrm{O} 2 \mathrm{SRF}-\mathrm{CPO}-27(\mathrm{Mg}), \mathrm{Zn}_{2}($ dhtp $)\left(\mathrm{H}_{2} \mathrm{O}\right)_{2} \cdot 8 \mathrm{H}_{2} \mathrm{O}$ $2 \mathrm{SRF}-\mathrm{CPO}-27(\mathrm{Zn})$ and $\mathrm{Ni}_{2}(\mathrm{dhtp})\left(\mathrm{H}_{2} \mathrm{O}\right)_{2} \cdot 8 \mathrm{H}_{2} \mathrm{O}$ 2SRF-CPO-27(Ni). $\mathrm{Na}_{2}$ (dhtp) $\cdot 2 \mathrm{H}_{2} \mathrm{O}\left(0.48 \mathrm{~g}, 1.7 \times 10^{-3} \mathrm{~mol}\right)$ was dissolved in $15 \mathrm{ml}$ of water. The appropriate metal salt $\left[\mathrm{Mg}\left(\mathrm{NO}_{3}\right)_{2} \cdot 6 \mathrm{H}_{2} \mathrm{O}, 1.51 \mathrm{~g}\right.$, $\mathrm{Zn}(\mathrm{OAc})_{2} \cdot 2 \mathrm{H}_{2} \mathrm{O}, 1.31 \mathrm{~g}$ or $\left.\left.\mathrm{Ni}(\mathrm{OAc})_{2} \cdot 4 \mathrm{H}_{2} \mathrm{O}, 1.47 \mathrm{~g}\right)\right]\left(5.9 \times 10^{-3}\right.$ $\mathrm{mol}$ ) dissolved in $10 \mathrm{ml}$ of water, was added to the linker solution under stirring and refluxed for 24 hours. The resulting products were filtered, washed with water and dried overnight in air.

$\mathrm{Zn}_{2}(\mathrm{dhtp})\left(\mathrm{H}_{2} \mathrm{O}\right)_{2} \cdot 8 \mathrm{H}_{2} \mathrm{O}$ 2SRT-CPO-27( $\left.\mathrm{Zn}\right)$ and $\mathrm{Ni}_{2}($ dhtp $)-$ $\left(\mathrm{H}_{2} \mathrm{O}\right)_{2} \cdot 8 \mathrm{H}_{2} \mathrm{O} 2 \mathrm{SRT}-\mathrm{CPO}-27(\mathrm{Ni})$. In a typical small scale reaction, $\mathrm{Zn}(\mathrm{OAc})_{2} \cdot 2 \mathrm{H}_{2} \mathrm{O}\left(1.14 \mathrm{~g}, 5.2 \times 10^{-3} \mathrm{~mol}\right)$ or $\mathrm{Ni}(\mathrm{OAc})_{2} \cdot 4 \mathrm{H}_{2} \mathrm{O}$ $\left(1.29 \mathrm{~g}, 5.2 \times 10^{-3} \mathrm{~mol}\right)$ was dissolved in $15 \mathrm{ml}$ of water. $\mathrm{Na}_{2}$ (dhtp) $\cdot 2 \mathrm{H}_{2} \mathrm{O}\left(0.48 \mathrm{~g}, 1.72 \times 10^{-3} \mathrm{~mol}\right)$, dissolved in water $(15 \mathrm{ml})$, was added to the solution under stirring. After the desired time (typically 4 hours) at $303 \mathrm{~K}(\mathrm{Zn})$ or $323 \mathrm{~K}(\mathrm{Ni})$, the resulting product was filtered, washed with water and dried in air overnight.

One-step method under reflux and at room temperature

$\mathrm{Zn}_{2}(\mathrm{dhtp})\left(\mathrm{H}_{2} \mathrm{O}\right)_{2} \cdot 8 \mathrm{H}_{2} \mathrm{O}$ 1SRF-CPO-27( $\left.\mathrm{Zn}\right), \mathrm{Ni}_{2}(\mathrm{dhtp})\left(\mathrm{H}_{2} \mathrm{O}\right)_{2} \cdot 8 \mathrm{H}_{2} \mathrm{O}$ 1SRF-CPO-27(Ni), $\mathrm{Zn}_{2}(\mathrm{dhtp})\left(\mathrm{H}_{2} \mathrm{O}\right)_{2} \cdot 8 \mathrm{H}_{2} \mathrm{O}$ 1SRT-CPO-27( $\left.\mathrm{Zn}\right)$ and $\mathrm{Ni}_{2}(\mathrm{dhtp})\left(\mathrm{H}_{2} \mathrm{O}\right)_{2} \cdot 8 \mathrm{H}_{2} \mathrm{O}$ 1SRT-CPO-27(Ni). In a typical small scale reaction, $\mathrm{Zn}(\mathrm{OAc})_{2} \cdot 2 \mathrm{H}_{2} \mathrm{O}\left(1.14 \mathrm{~g}, 5.2 \times 10^{-3} \mathrm{~mol}\right)$ or $\mathrm{Ni}(\mathrm{OAc})_{2} \cdot 4 \mathrm{H}_{2} \mathrm{O}\left(1.29 \mathrm{~g}, 5.2 \times 10^{-3} \mathrm{~mol}\right)$ was dissolved in $15 \mathrm{ml}$ of water. $\mathrm{H}_{2}$ (dhtp) $\left(0.34 \mathrm{~g}, 1.72 \times 10^{-3} \mathrm{~mol}\right)$, dissolved in aqueous $\mathrm{NaOH}(0.46 \mathrm{M}, 15 \mathrm{ml})$, was added to the metal solution under stirring. The reaction temperature was adjusted accordingly (e.g. maintained at room temperature for 1SRT-CPO-27(Zn) and 1SRT-CPO-27(Ni) or heated to reflux for 1SRF-CPO-27(Zn) and (Ni)) and the mixtures stirred for the desired length of time (typically 6 hours). The resulting products were filtered, washed with water and dried in air overnight.

\section{Characterization techniques}

Powder X-ray diffraction data (PXRD) were collected on a Panalytical Empyrean diffractometer operating $\mathrm{Cu} \mathrm{K}_{1}$ radiation monochromated with a curved Ge(111) crystal in reflectance mode. Thermogravimetric analysis (TGA) was conducted on a Perkin-Elmer Diamond pris Thermal Analyser using a heating rate of $5 \mathrm{~K} \mathrm{~min}^{-1}$ from room temperature to $873 \mathrm{~K}$ under a flowing air atmosphere. SEM images were obtained on a JEOL 5600 scanning electron microscope (SEM). Particle size distributions were recorded on reaction slurries prior to filtration using a Malvern Instruments Mastersizer 2000 laser diffraction analyser. Samples were dispersed in a water bath with mechanical stirring. In situ particle size measurements were recorded during selected medium scale syntheses using a Mettler Toledo Particle Track FBRM G400 probe. Adsorption isotherms for $\mathrm{N}_{2}$ at $77 \mathrm{~K}$ were measured on a Tristar II volumetric apparatus. The as-prepared samples were activated at $423 \mathrm{~K}$ for $8-12$ hours prior to measurement. All measurements were conducted on as-prepared samples that were stored in capped (but not air-tight) glass vials at room temperature. The materials were not handled under inert atmospheres because this is impractical during NO loading and release measurements.

\section{NO adsorption, desorption and release measurements}

Thermodynamic adsorption/desorption isotherm. The nitric oxide adsorption/desorption profiles for the as prepared MOFs were collected using a bespoke gravimetric adsorption system. This system consists of a highly sensitive microbalance (sensitivity of $0.1 \mu \mathrm{g}$ and a reproducibility of $0.01 \%$ ) and pressure gauge. Each sample was dehydrated at $423 \mathrm{~K}$ under a pressure of $\times 10^{-5}$ mbar overnight until no further mass loss was observed. The samples were cooled to $298 \mathrm{~K}$ using a water bath (temperature accuracy of $0.02 \mathrm{~K}$ ). Nitric oxide gas was incrementally introduced to the system and, after each introduction, the recorded mass of the sample was allowed to stabilise before the next NO addition was made. The adsorption process was deemed to be complete when the introduced pressure of NO was equal to atmospheric pressure. The desorption profile is measured by exposing the sample to incremental reductions in pressure to a final pressure of $\times 10^{-2}$ mbar.

Kinetic NO release measurement. Activation is achieved by heating the framework under vacuum, resulting in the production of a high number of accessible CUS which, on exposure to gas, strongly bind NO forming a metal-NO adduct. The NO release is triggered by exposure to humidity at room temperature. Samples ( $25 \mathrm{mg})$ were loaded into glass vials, placed in a Schlenk tube and heated under vacuum $\left(\times 10^{-5}\right.$ mbar $)$ to an activation temperature of $423 \mathrm{~K}$ as determined by TGA (see discussion section). The dehydrated powders were exposed to $\sim 1$ bar of NO for 30 minutes. Excess NO was removed with vacuum and the samples were flushed with dry argon prior to sealing.

The release of NO was measured using a Sievers NOA 280i chemiluminescence nitric oxide analyser. Samples were transferred to a chamber that is connected to the analyser and through which flows humid nitrogen gas (humidity controlled at $11 \% \mathrm{RH})$. The humid gas triggers the release of NO and carries it to the analyser. The amount of nitric oxide released is measured using the chemiluminescence reaction between nitric oxide and ozone $\left(\mathrm{O}_{3}\right)$ :

$$
\begin{gathered}
\mathrm{NO}+\mathrm{O}_{3} \rightarrow \mathrm{NO}_{2}^{*}+\mathrm{O}_{2} \\
\mathrm{NO}_{2}^{*} \rightarrow \mathrm{NO}_{2}+h \nu
\end{gathered}
$$


The emission from the excited nitrogen dioxide $(h \nu)$ is detected using a red-sensitive photomultiplier detector. The level of NO present in the carrier gas is recorded (in ppm or $\mathrm{ppb}$ ) each second until data collection is stopped. Measurements were stopped once NO levels had dropped to an arbitrary value of $20 \mathrm{ppb}$ (a value nearing the limit of the instrument resolution). Data were transformed from $\mathrm{ppb}$ and ppm to mmol $\mathrm{g}^{-1}$ and finally molecules per unit cell. Summation of the data produced a plot of total NO release over time. Note that the time taken to reach $20 \mathrm{ppb}$ can vary between samples and is a further performance metric.

Adsorption, storage and release data are presented below as molecules of NO per MOF unit cell (instead of the more commonly used mmol $\mathrm{g}^{-1}$ ) to enable fair comparison between materials of different composition. The data are presented in the more conventional units of $\mathrm{mmol} \mathrm{g}^{-1}$ of MOF in ESI. $\dagger$

The research data supporting this publication can be accessed at http://dx.doi.org/10.17630/85aa840e-aaf0-4c57-90b7cb30df6076e7

\section{Results and discussion}

\section{Materials prepared from two-step processes}

Powder products were obtained from all reflux reactions employing $\mathrm{Na}_{2}$ (dhtp) $\cdot 2 \mathrm{H}_{2} \mathrm{O}$ as the linker source, water as the main solvent and either $\mathrm{Mg}^{2+}, \mathrm{Zn}^{2+}$ or $\mathrm{Ni}^{2+}$ as the metal species. Ni and $\mathrm{Zn}$-based products were also obtained from the lower temperature method using the same benign solvent system, however CPO-27( $\mathrm{Mg})$ failed to crystallise under these conditions. This may be a direct result of the water-rich system since, for example, Dietzel et al. reported the formation of a yellow precipitate (presumably $\mathrm{CPO}-27(\mathrm{Mg})$ ) at room temperature during mixing of reagents (THF, $\mathrm{NaOH}, \mathrm{Mg}$ nitrate and water) prior to solvothermal treatment. ${ }^{14}$ It was further observed that, while CPO-27(Zn) crystallises quickly at room temperature reaching a maximum yield in a few hours, CPO-27(Ni) is slower to form (Fig. 1). This rate of crystallisation, as well as overall yield, can be easily increased by raising

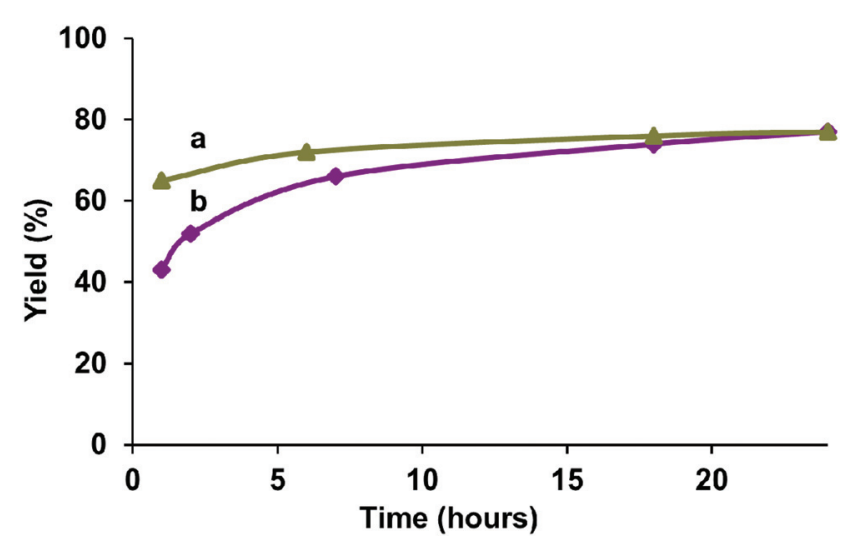

Fig. 1 Variation of percentage yield versus time for (a) 2SRT-CPO-27(Zn) and (b) 2SRT-CPO-27(Ni). the temperature even by as little as 30 degrees, reaching $75-85 \%$ yield in 6 hours.

PXRD analysis of the products (Fig. 2) confirms that each possesses the $\mathrm{CPO}-27$ structure and that they are of single phase, however CPO-27(Ni) prepared at low temperature is of significantly lower crystallinity compared to its reflux and solvothermal counterparts. The use of room temperature conditions did not, however, adversely affect CPO-27(Zn), which exhibits very good crystallinity when synthesised under these conditions.

Examination of the products from two-step processes by SEM (Fig. 3) reveals notable differences in crystal size and morphology depending on the metal employed and whether room temperature, reflux or solvothermal conditions are used. When prepared solvothermally, CPO-27( $\mathrm{Mg})$ exhibits blocky rodshaped crystals that appear to grow together in floret-like arrangements; however when prepared under reflux conditions the material exhibits discrete crystals of uniform size. CPO-27(Zn) forms needle-shaped crystals and exhibits a reduction in crystal size when moving to lower temperature, and a tendency to form as floret-like intergrowths under room temperature conditions. In contrast, CPO-27(Ni) presents particles of much smaller granulation and no discernable morphology, regardless of synthesis temperature, in line with previously reported observations. $^{22}$ Further alterations in the morphology and surface quality of $\mathrm{CPO}-27(\mathrm{Zn})$ crystals are observed when moving to a one-step process and when conducting the synthesis at different scales. This behaviour and its potential consequence are discussed later.

A notable difference between materials produced via the different methods is the variation in BET-measured surface areas (ESI Table $1 \dagger$ ). The measured surface areas are generally

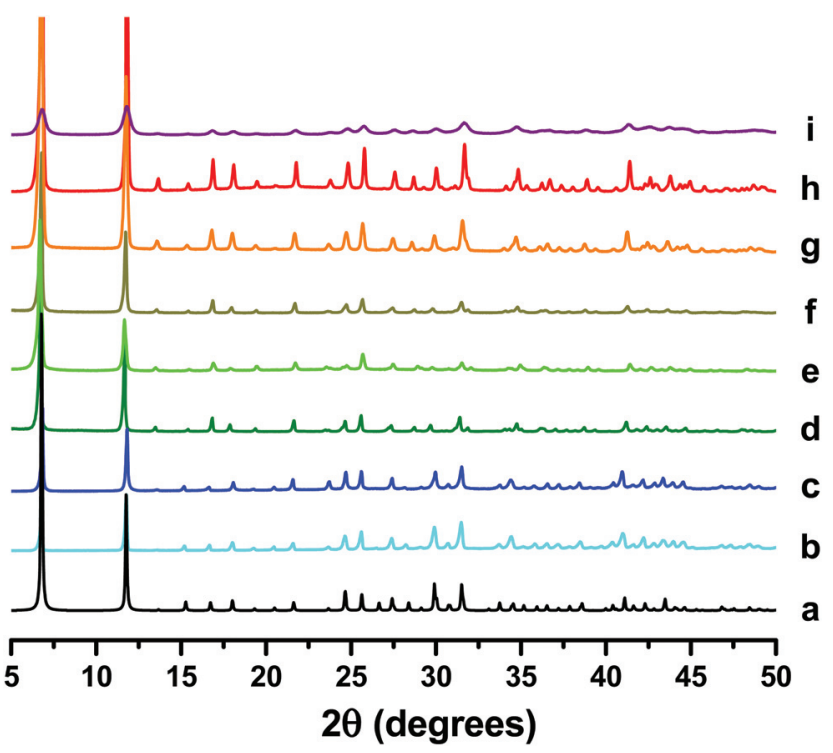

Fig. 2 PXRD patterns of (a) reference CPO-27(Mg), ${ }^{14}$ (b) Solv-CPO-27(Mg), (c) 2SRF-CPO-27(Mg), (d) Solv-CPO-27(Zn), (e) 2SRF-CPO-27(Zn), (f) 2SRTCPO-27(Zn), (g) Solv-CPO-27(Ni), (h) 2SRF CPO-27(Ni) and (i) 2SRTCPO-27(Ni). 

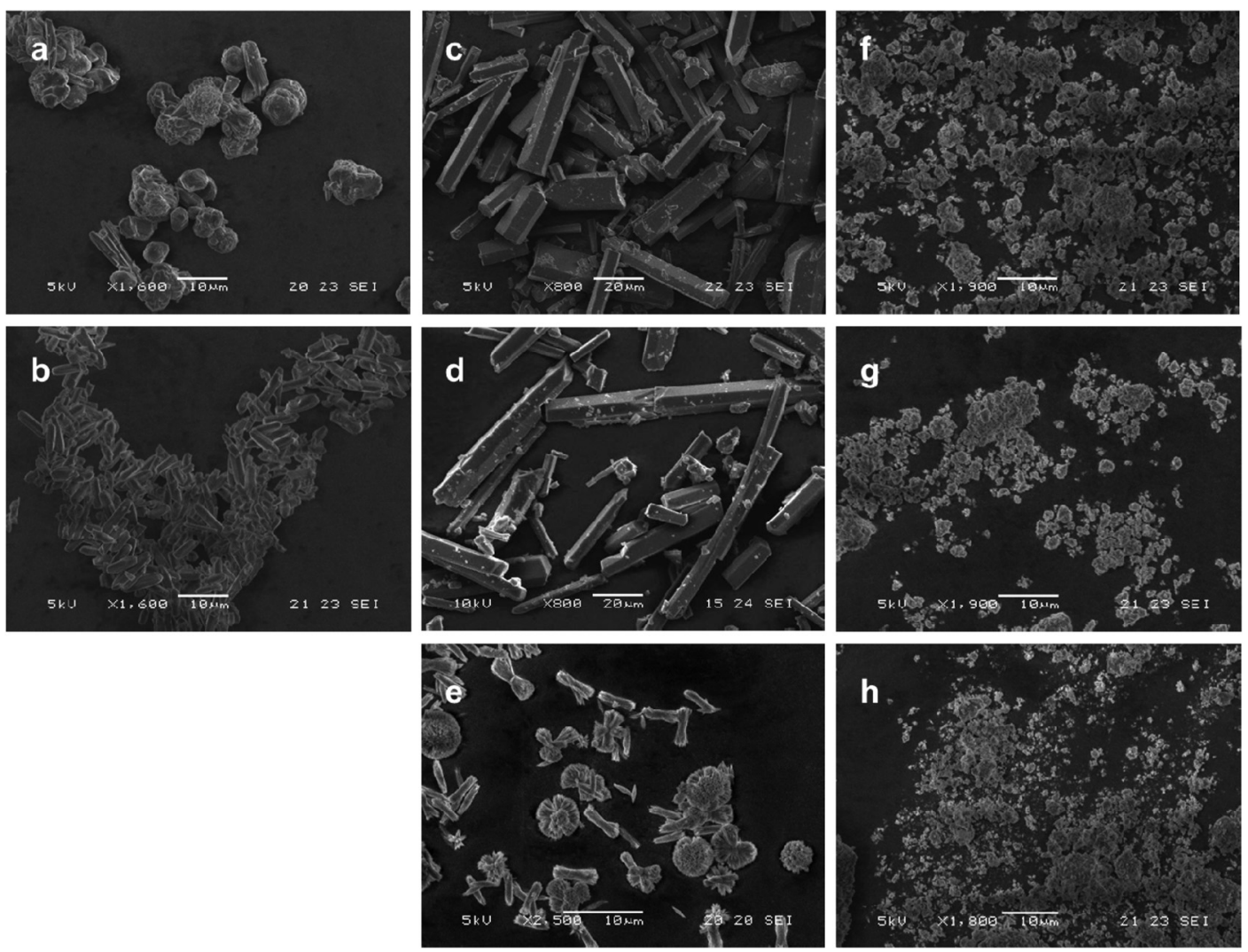

Fig. 3 Representative SEM images of (a) Solv-CPO-27 (Mg), (b) 2SRF-CPO-27(Mg), (c) Solv-CPO-27(Zn), (d) 2SRF-CPO-27(Zn), (e) 2SRT-CPO-27(Zn), (f) Solv-CPO-27(Ni), (g) 2SRF-CPO-27(Ni) and (h) 2SRT-CPO-27(Ni).

lower than those reported in the literature for similar materials, although wide variation was reported by Dietzel et al. depending on the way in which the MOFs are treated. ${ }^{14}$ The lower values reported herein may be due to the fact that the samples were not handled and stored under inert conditions. This has been reported to be important particularly for $\mathrm{CPO}-27(\mathrm{Mg}),{ }^{23}$ although we note that a measurement of over $1000 \mathrm{~m}^{2} \mathrm{~g}^{-1}$ was still recorded for 2SRF-CPO-27(Mg). The lower and variable measurements may therefore be due to the synthesis method. However, as will be discussed later, lower BET surface area values do not necessarily correlate with poorer NO adsorption and release.

It is widely accepted that in order to achieve optimum gas adsorption in MOFs they must be activated (often by heating) to remove adsorbed solvent and guest species. It is common practice to exchange the adsorbed solvent, where appropriate, with a lower boiling or more labile one prior to attempting activation. Gravimetric analyses showing NO uptake and storage for activated Solv-CPO-27( $\mathrm{Zn})$ and $(\mathrm{Mg})$ with and without solvent exchange treatment are shown in Fig. 4 (ESI Fig. $1 \dagger$ ) (solvent exchange is not necessary for Solv-CPO-27(Ni)).

It can be observed from the data that solvent exchange prior to activation does indeed result in higher NO uptake and storage by solvothermally prepared $\mathrm{CPO}-27(\mathrm{Zn})$ and $(\mathrm{Mg})$, confirming the need for this step in order to maximise perform-

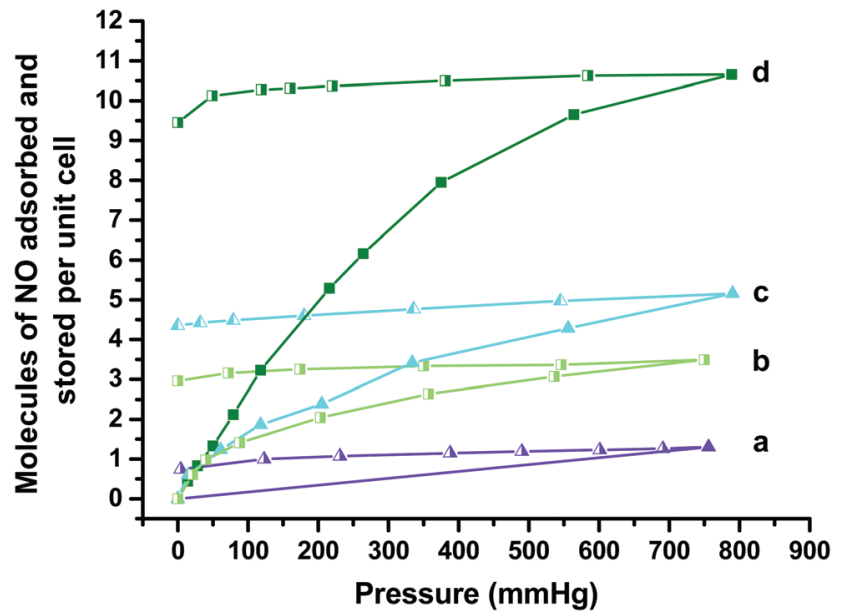

Fig. 4 Adsorption $-\square-$ and desorption $-\square-$ isotherms of $\mathrm{NO}$ at $298 \mathrm{~K}$ (measured using gravimetric analysis) plotted as molecules of NO per unit cell against change of pressure for (a) Solv-CPO-27(Mg) as prepared, (b) Solv-CPO-27(Zn) as prepared, (c) Solv-CPO-27(Mg) after solvent exchange and (d) Solv-CPO-27(Zn) after solvent exchange.

ance for these materials. Therefore, to set the most stringent benchmark for the reflux- and room temperature-prepared materials, NO adsorption and release data for these samples 
are compared in subsequent charts to data from the equivalent solvent exchanged solvothermal products. We postulated that materials synthesised via water-based reflux and lower temperature methods would not require solvent exchange and would only require activation. These products were therefore not solvent exchanged prior to activation and NO analysis. Neither were they exhaustively washed, for example in methanol as reported elsewhere,$^{20}$ prior to use. If successful without such post treatment, the manufacturing time would be significantly reduced.

The temperature of activation was identified by TGA (ESI Fig. $2 \dagger$ ), which, although suggests differences in stability at high temperature, indicates a temperature window ranging from $393 \mathrm{~K}$ to $523 \mathrm{~K}$ for all samples where the frameworks are dehydrated and stable. The temperature of activation was set at $423 \mathrm{~K}$ (under vacuum) - much lower than the previously reported activation temperature for these materials, see Table 1. On dehydration, there was a change in colour from yellow to pale yellow for $\mathrm{CPO}-27(\mathrm{Mg})$ and $(\mathrm{Zn})$, and mustard colour for $\mathrm{CPO}-27(\mathrm{Ni})$ as a result of changing metal coordination and the formation of the CUSs. Exposure to NO gas resulted in an immediate further colour change to darker yellow-green (which is more evident in $\mathrm{CPO}-27(\mathrm{Mg})$ and $(\mathrm{Zn})$ samples) indicating the formation of a metal-NO adduct. It is the strength of this adduct that partly determines the storage and release properties of NO from these types of materials. ${ }^{6}$ The NO is released by exposure to a moist atmosphere at room temperature, i.e. exchange of NO for water with regeneration of the starting material.

Gravimetric analyses of NO adsorption and desorption (storage) by products prepared under reflux are compared to those of equivalent solvent exchanged, solvothermally prepared products in Fig. 5 (ESI Fig. $3 \dagger$ ). Data are currently unavailable for products prepared at room temperature. The data clearly

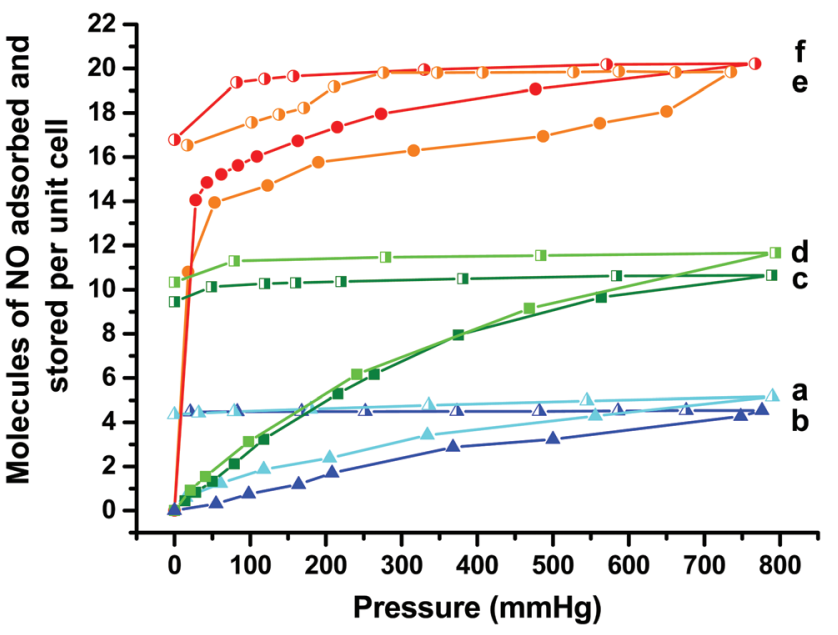

Fig. 5 Adsorption $-\square-$ and desorption $-\square-$ isotherms of $\mathrm{NO}$ at $298 \mathrm{~K}$ for (a) Solv-CPO-27 (Mg) after solvent exchange, (b) 2SRF-CPO-27(Mg), (c) Solv-CPO-27(Zn) after solvent exchange, (d) 2SRF-CPO-27(Zn), (e) Solv-CPO-27 (Ni) without solvent exchange and (f) 2SRF-CPO-27(Ni). illustrate that $\mathrm{CPO}-27(\mathrm{Zn})$ and $(\mathrm{Mg})$ prepared from reflux methods, and not solvent exchanged prior to activation, show equal performance to their solvent exchanged, solvothermally prepared counterparts. This is despite the noticeable differences in surface area observed between these samples (ESI Table $1 \dagger$ ), perhaps indicating that surface area measured by nitrogen adsorption is not necessarily a reliable indicator of good NO adsorption and storage capacity. Apparent low surface area measured by nitrogen adsorption may be due to incomplete removal of tightly bound solvent molecules from the internal surface. However, it may also be a result of surface effects blocking access to nitrogen. It is possible that such effects are overcome when using a more strongly coordinating gas (i.e. NO) and by conducting the adsorption at higher temperature.

The data also confirm our view that a solvent exchange step would be unnecessary for these products. Differences in performance are, however, observed between the different compositions suggesting a metal-dependent response. Such a phenomenon has been reported in other adsorption studies, for example the adsorption of $\mathrm{CO}_{2}{ }^{11}$ and $\mathrm{H}_{2}{ }^{24}$ by CPO-27 MOFs of different compositions.

Activated Solv-CPO-27(Ni) adsorbs $\sim 20$ molecules of NO per unit cell (Fig. 5, ESI Fig. $3 \dagger$ ). The desorption isotherm indicates a loss of $\sim 3$ molecules per unit cell of physisorbed gas from the porous network resulting in a stored capacity of $\sim 17$ molecules per unit cell (maximum theoretical value is 18 molecules per unit cell). In contrast, after activation, both Solv- and 2SRF-CPO-27(Mg) adsorb a total of only $\sim 5$ molecules of NO per unit cell (Fig. 5, ESI Fig. $3 \dagger$ ). However, during the reapplication of vacuum, the NO level remains constant, indicating that the quantity of NO adsorbed is equal to that stored. Analysis of activated Solv- and 2SRF-CPO-27( $\mathrm{Zn})$ reveals uptake and storage levels intermediate between those of CPO-27( $\mathrm{Mg})$ and $\mathrm{CPO}-27(\mathrm{Ni})$. As observed with $\mathrm{CPO}-27(\mathrm{Ni})$, the desorption isotherms for these $\mathrm{Zn}$ analogues illustrate loss of $\mathrm{NO}$, giving a storage capacity of $\sim 10$ molecules per unit cell.

From these results alone, it may be concluded that the synthesis method has no effect on the performance of the material. However, differences are revealed when comparing the quantity of stored NO that can be released on exposure to moist atmosphere. Of course it is this property that is most important for biomedical applications requiring controlled NO delivery.

The total NO released over time from Solv-CPO-27(Ni) when exposed to moist atmosphere reaches up to 17 molecules per unit cell over 20 hours (Fig. 6, ESI Fig. 4†), highlighting an almost completely reversible release of the chemisorbed nitric oxide. These data are in good agreement with previously reported values. ${ }^{6}$ Similar performance is observed from the reflux product although perhaps slightly less of the stored NO is released. In contrast, when the synthesis is conducted at room temperature, the quantity of NO released and the time scale in which it takes place is dramatically reduced. Possible causes of this are discussed later. On exposing Solv- and 2SRF-CPO-27(Mg) to humidity (Fig. 6, ESI Fig. $4 \dagger$ ) only $\sim 0.07$ of the 4 molecules of NO stored per unit 

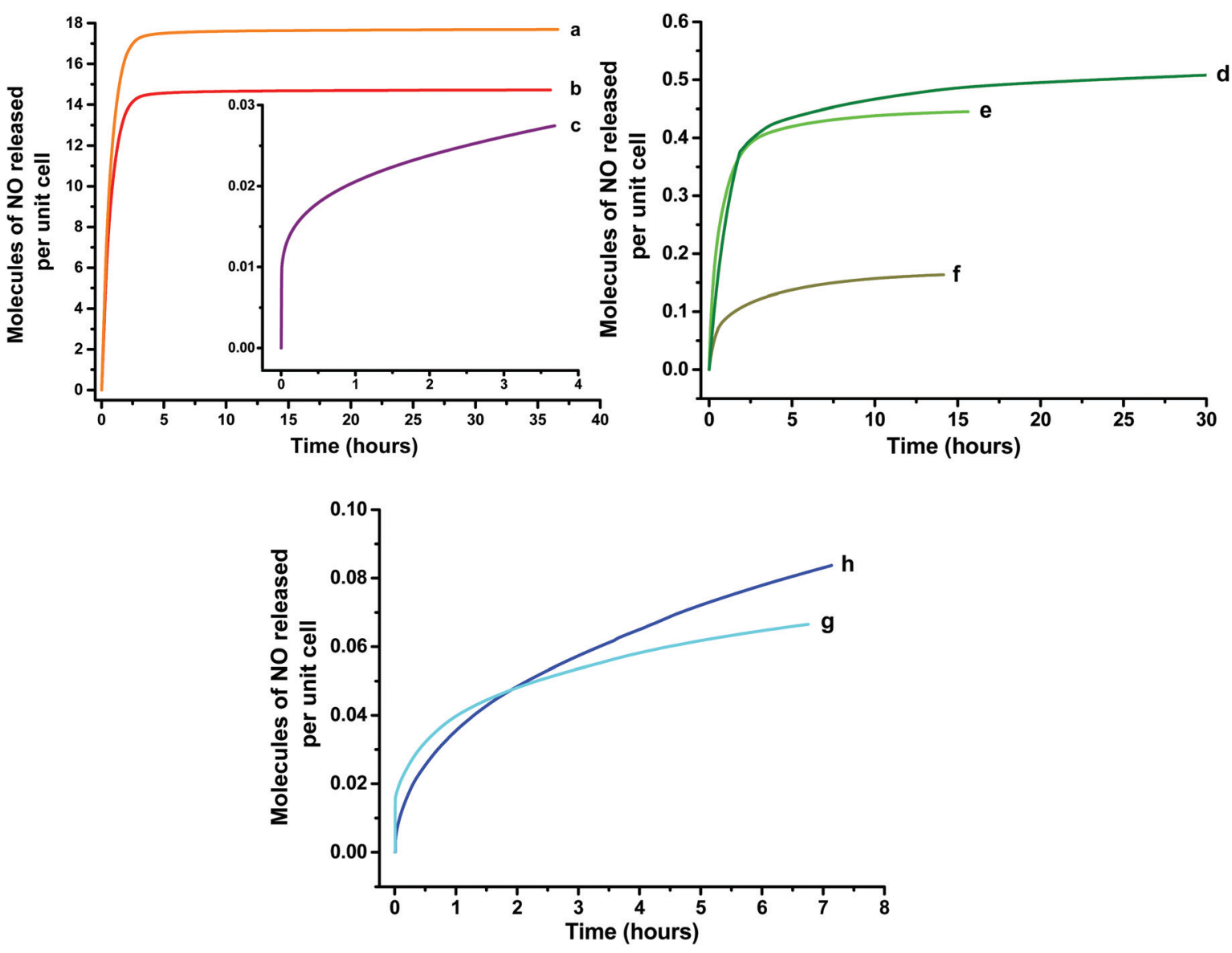

Fig. 6 Total NO release (measured using chemiluminescence analysis) on contact with humid atmosphere (11\% RH) for (a) Solv-CPO-27(Ni), (b) 2SRF-CPO-27(Ni), (c) 2SRT-CPO-27(Ni), (d) Solv-CPO-27(Zn), (e) 2SRF-CPO-27(Zn), (f) 2SRT-CPO-27(Zn), (g) Solv-CPO-27(Mg) and (h) 2SRFCPO-27(Mg). Data collection was stopped when NO levels reached 20 ppb.

cell are liberated, suggesting that the stored NO is tightly bound within the framework. Since both $\mathrm{CPO}-27(\mathrm{Mg})$ products exhibit the same result, it is probable that the method of synthesis is not responsible for these effects. Rather, we suggest that this material is more difficult to fully dehydrate (in accord with observations published previously by Dietzel et $a l .{ }^{14}$ ) and that the metal used (magnesium) has a high, non-reversible affinity for NO. We are presently conducting further analysis to ascertain the heats of adsorption and desorption of NO in CPO-27 MOFs. CPO-27(Zn) exhibits intermediate NO release performance between those of its $\mathrm{Ni}$ and $\mathrm{Mg}$ counterparts. When prepared under reflux (using $\mathrm{Na}_{2}$ (dhtp). $2 \mathrm{H}_{2} \mathrm{O}$ and water) the total level of NO that is released is comparable to that from the solvothermally prepared product, which is approximately $5 \%$ of the stored capacity. However, the dose period is much shorter from the reflux product. As observed for $\mathrm{CPO}-27(\mathrm{Ni})$ there is a significant reduction in total NO release when the material is prepared at room temperature, although the level released may still be adequate for many biomedical applications (where often only ppb levels of NO are required ${ }^{9,25}$ ). Possible causes for these variations are discussed later.

\section{Materials prepared from one-step processes}

A single step process was investigated in order to simplify the synthesis procedure with a view to future scale up. In this approach, the $\mathrm{NaOH} / \mathrm{dhtp}$ solution is dosed directly to the metal salt solution, avoiding the need to isolate the $\mathrm{Na}_{2}$ (dhtp) $2 \mathrm{H}_{2} \mathrm{O}$ salt. This method was trialled for CPO-27(Ni) and (Zn) under both reflux and room temperature conditions, focusing on the impact it may have on total NO release performance. PXRD patterns of representative products, confirming phase identity and purity, are illustrated in Fig. 7 (note that reaction scales given in the text refer to vessel volume, often operated at $50-75 \%$ capacity). In accord with the findings from the twostep process, the crystallinity of $\mathrm{CPO}-27(\mathrm{Zn})$ samples is consistently high for all samples. In contrast, Ni-based samples prepared from the one-step room temperature process show improved crystallinity over their two-step counterparts, while those prepared from a one-step reflux process show poorer crystallinity compared to their two-step counterparts.

Interestingly, the total amount of NO released from products prepared under reflux conditions was adversely affected when using this one-step approach - reduced from 


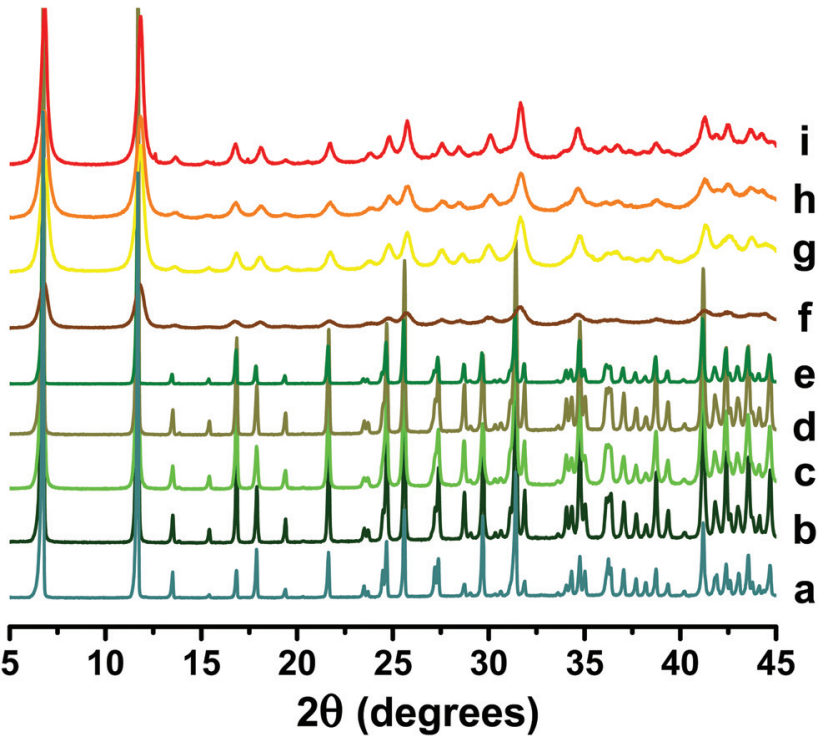

Fig. 7 PXRD patterns for (a) 1SRF-CPO-27(Zn), 1SRT-CPO-27(Zn) synthesised at (b) $100 \mathrm{ml}$, (c) $1 \mathrm{~L}$, (d) $20 \mathrm{~L}$, (e) $100 \mathrm{~L}$ and (f) 1SRF-CPO-27(Ni), 1SRT-CPO-27(Ni) synthesised at (g) $100 \mathrm{ml}$, (h) $1 \mathrm{~L}$ and (i) $20 \mathrm{~L}$ scales.

approximately 14 to 11 molecules per unit cell for CPO-27(Ni) and from approximately 0.4 to 0.2 molecules per unit cell for CPO-27(Zn) (Fig. 8, ESI Fig. $5 \dagger$ ). However, the performance of Ni-based products prepared at low temperature was actually improved compared to equivalent materials prepared via the two-step process - releasing $\sim 8$ molecules per unit cell. Znbased products prepared at room temperature performed as well as equivalent materials prepared via the two-step approach, releasing approximately 0.1 molecules per unit cell. These results suggest that the NO release performance may be influenced by different factors depending on the MOF composition. This is discussed in more detail below.

\section{Scale up}

Due to their superior NO release performance, only CPO-27(Zn) and $\mathrm{CPO}-27(\mathrm{Ni})$ were studied for scale up. Although the low temperature products exhibit lower NO release performance compared to two-step reflux and solvothermal products, the quantity released is still more than adequate for many biomedical applications. Therefore, in balancing ease of synthesis, environmental credentials, energy consumption and required product performance, the lower temperature one-step options were selected for scale up. However, in a compromise to maximise yields from $\mathrm{CPO}-27(\mathrm{Ni})$ synthesis without adding undue time to the process, these reactions were conducted at 323-333 K. Concentrations were kept relatively low (i.e. close to those of small scale syntheses) for this first proof of concept work, with the intention of increasing throughputs in future work. After optimising the process to take the foregoing points into account, the syntheses were scaled in stages from $100 \mathrm{ml}$ to $1 \mathrm{~L}$ then to a $20 \mathrm{~L}$ vessel. Finally, the synthesis of CPO-27(Zn) was scaled to $100 \mathrm{~L}$ vessel.

CPO-27(Ni). The main issue in scaling up the water-based synthesis of $\mathrm{CPO}-27(\mathrm{Ni})$ was recovering the product in an acceptable time scale. Generally, this $\mathrm{CPO}-27(\mathrm{Ni})$ product filters very slowly when prepared in this way, in direct contrast to its $\mathrm{Zn}$ and $\mathrm{Mg}$ counterparts. We attribute this behaviour to the differences in particle size between the three isotypes, as evidenced in the SEM micrographs above (see Fig. 3). Particle size distribution measurements (Fig. 9) of reaction slurries taken prior to filtration further indicate the disparity between size distributions of $\mathrm{Zn}$ and Ni-based products. A bi-modal distribution is also observed that may indicate the presence of agglomerates as well as primary particles. This is particularly
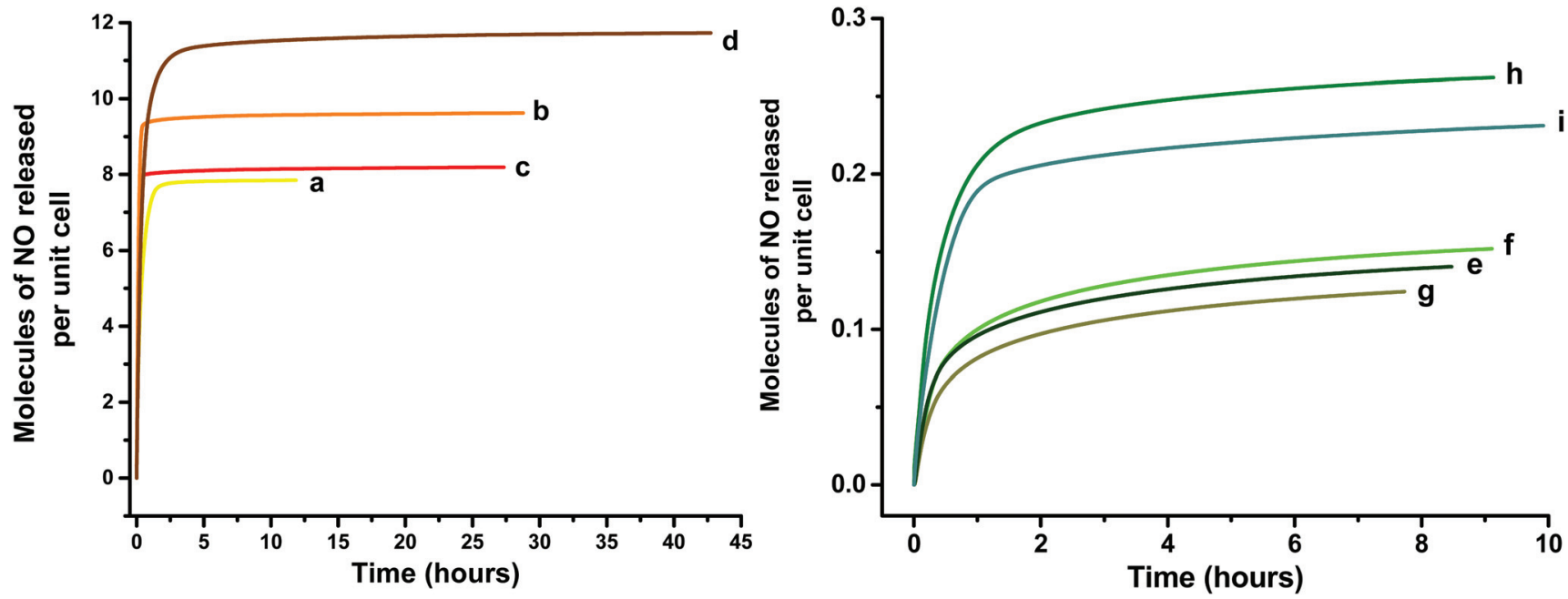

Fig. 8 Total NO release on contact with humid atmosphere (11\% RH) for (a) 1SRT-CPO-27(Ni) $100 \mathrm{ml}$, (b) 1SRT-CPO-27(Ni) 1 L, (c) 1SRT-CPO-27(Ni) $20 \mathrm{~L}$, (d) 1SRF-CPO-27(Ni) 100 ml, (e) 1SRT-CPO-27(Zn) 100 ml, (f) 1SRT-CPO-27 (Zn) 1 L, (g) 1SRT-CPO-27(Zn) 20 L, (h) 1SRT-CPO-27(Zn) 100 L and (i) 1SRF-CPO-27 (Zn) $100 \mathrm{ml}$. Data collection was stopped when NO levels reached $20 \mathrm{ppb}$. 


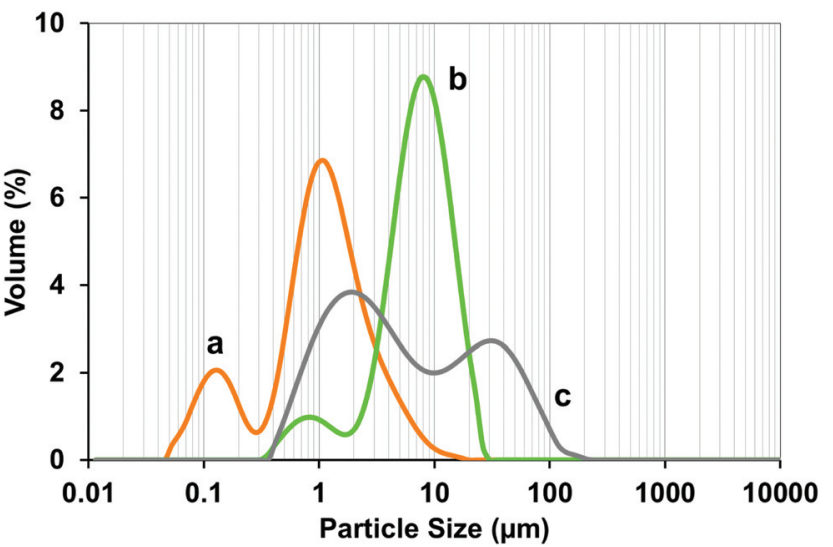

Fig. 9 Representative particle size distributions of reaction slurries for (a) 1SRT-CPO-27(Ni) without optimisation for filtration, (b) 1SRTCPO-27(Zn) and (c) 1SRT-CPO-27(Ni) with altered dose rate and stir-out time to afford faster filtration.

evident in the case of CPO-27(Ni). One may speculate that such a distribution may also favour the formation of a dense filter cake resulting in slower filtration. Changing reaction temperature (e.g. reflux vs. room temperature) did not improve filtration characteristics. Instead, our preliminary development data suggest that the interplay between reaction duration and dose rate is more important. For example, Table 2 illustrates the difference in filtration times for a representative selection of reaction variants. Fig. 10a illustrates how the particle size distribution changes over a long period of time using in situ analysis during the mid-scale reactions. It can be observed for CPO-27(Ni) that the population of fine particles increases while that of larger particles decreases over time.

By tuning the addition rate and stir-out time it is therefore possible to reduce filtration times and facilitate larger scale production without recourse to more specialised recovery methods. Nevertheless, a compromise must be sought between allowing the reaction to proceed far enough to maximise yield, and preventing it from progressing so far that the population of fine particles becomes too high and prevents efficient recovery. PXRD patterns for products obtained from mid and large-scale syntheses indicate consistent purity and

Table 2 Representative filtration times versus rate of addition of linker solution and stir out time for 1SRT-CPO-27 (Ni). Time measured to draw $500 \mathrm{ml}$ of reaction liquor through $110 \mathrm{~mm}$ diameter Whatman 1 qualitative filter paper using a KNF laboport pump type N810.3FT.18 vacuum pump

\begin{tabular}{llc}
\hline $\begin{array}{l}\text { Addition } \\
\text { time }(\mathrm{h})\end{array}$ & $\begin{array}{l}\text { Stir out } \\
\text { time }(\mathrm{h})\end{array}$ & $\begin{array}{l}\text { Filtration } \\
\text { time }(\mathrm{min})\end{array}$ \\
\hline 1.25 & 3.5 & 4 \\
1.75 & 3.5 & 3 \\
2.25 & 3.5 & 10 \\
0.50 & 5.0 & 70
\end{tabular}

crystallinity (Fig. 7). Approximately $1 \mathrm{~kg}$ of material was recovered from the $20 \mathrm{~L}$ vessel, operated at three quarters capacity. The entire process from loading the vessel to drying the filter cake was conducted in a single day shift with a resultant yield of $85 \% \pm 5$. The total amount of NO released from products obtained at $1 \mathrm{~L}$ and $20 \mathrm{~L}$ scales are comparable to and possibly slightly higher than that of the small-scale product (Fig. 8, ESI Fig. $5 \dagger$ ) with the release period being slightly longer.

CPO-27(Zn). Due to its inherently larger crystallite size and narrower particle size distribution, $\mathrm{CPO}-27(\mathrm{Zn})$ does not suffer from the same filtration issues as $\mathrm{CPO}-27(\mathrm{Ni})$ and can be recovered very quickly. As with $\mathrm{CPO}-27(\mathrm{Ni})$, the forming precipitate dispersion progresses through a period of very large particles during the addition of linker solution to metal solution. However, in the case of $\mathrm{CPO}-27(\mathrm{Zn})$ these very large particles are short lived and the distribution quickly stabilises even before the end of the dosing period is reached (Fig. 10b). This more stable distribution removes the need to compromise between filtration rate and yield. As we have reported previously ${ }^{19}$ the main issue in synthesising this MOF is the formation of a secondary phase. This can be avoided by carefully tuning the $\mathrm{NaOH}$ : linker ratio - a ratio of approximately 3 is preferred. ${ }^{20}$ Approximately $1 \mathrm{~kg}$ of material was obtained from the $20 \mathrm{~L}$ vessel, while $4 \mathrm{~kg}$ were obtained from a $100 \mathrm{~L}$ vessel (Fig. 11) both operated at three quarters capacity over a single day shift. Further work has indicated that these throughputs can be easily doubled without compromising the product. PXRD patterns of the products (yield $80 \% \pm 5$ ) compare favourably with those of small scale samples (Fig. 7). NO release profiles for representative products prepared during scale-up are illustrated in Fig. 8. There is good consistency between profiles from $100 \mathrm{ml}, 1 \mathrm{~L}$ and $20 \mathrm{~L}$ scale products, with each releasing approximately 0.1 molecules per unit cell over a 9 hour period. The material obtained from the $100 \mathrm{~L}$ vessel released a higher level of NO over a longer period of time and shows similar performance to that of 2SRF-CPO-27(Zn).

\section{Postulated reasons for differences in NO release}

The NO release data presented above indicates a broad variation in total NO release and duration of release obtained from each isotype depending on the metal and synthesis method employed. As outlined above, the general trend in total $\mathrm{NO}$ release (i.e. $\mathrm{Ni}>\mathrm{Zn}>\mathrm{Mg}$ ) can be explained by the differences in affinity towards NO and ease of dehydration of the respective metals. However, variations are also observed for each composition depending on which synthesis conditions were employed. In the case of $\mathrm{CPO}-27(\mathrm{Ni})$, there appears to be a trend to lower total NO release and shorter dose periods with lower reaction temperature. Typically surface area is often presented as an indicator of gas storage/release potential (along with other features such as CUSs). Indeed, by plotting the NO release parameters vs. BET-measured surface area (ESI Fig. $6 \dagger$ ) a possible trend is revealed in which lower release levels and shorter release timescales are obtained from materials with lower surface area. The reduction in surface 
(a)

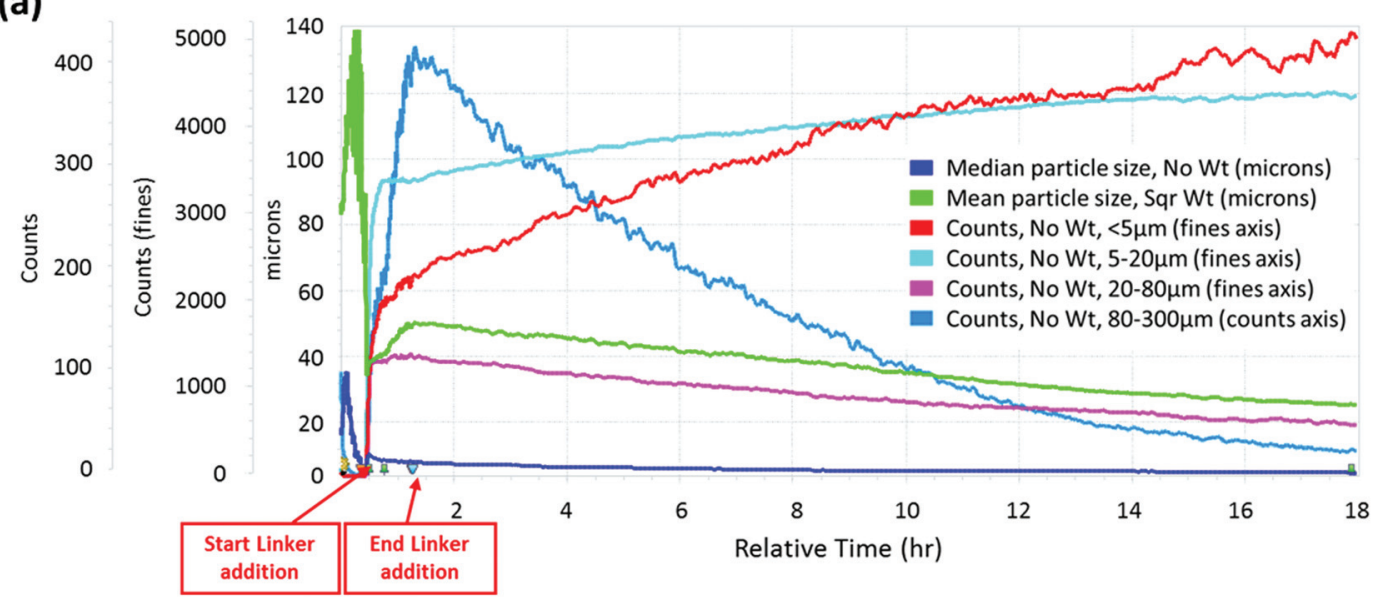

(b)

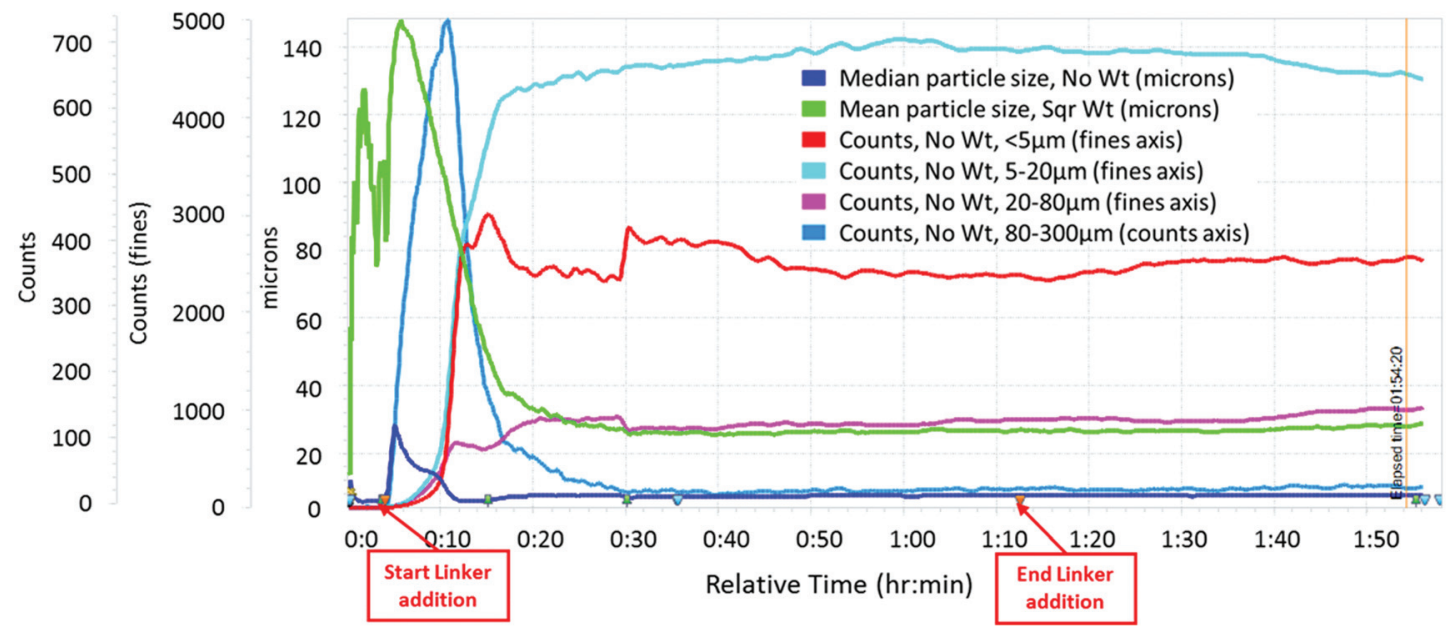

Fig. 10 In situ particle size measurements versus time for (a) 1SRT-CPO-27(Ni) and (b) 1SRT-CPO-27(Zn), showing mean and median particle size (microns) and the growth/decay of selected particle size groupings.

area with synthesis temperature coincides with a reduction in crystallinity (Fig. 2 and 7).

However, unlike $\mathrm{CPO}-27(\mathrm{Ni})$, the variation in $\mathrm{NO}$ release properties observed between $\mathrm{CPO}-27(\mathrm{Zn})$ materials prepared under different conditions and scales shows no correlation with BET surface area (ESI Fig. $6 \dagger$ ), which is reasonably consistent across all samples. Nor can it be attributed to crystallinity since this appears to be constant across all samples (Fig. 7). It is also unlikely to be linked to particle size and morphology, despite large variations in these properties being observed between products prepared in different ways (ESI Fig. $7 \dagger$ ). It is possible that residual sodium acetate present in the products may partially block access to the MOF pores and CUSs; however this effect would be present in all samples and is not expected therefore to cause such a wide variation in performance. Closer inspection of the SEM images of each product suggests that higher NO release performance is obtained from samples with clean and evenly formed surfaces, suggesting that the NO release performance is partly governed by a surface effect, and that controlling the surface characteristics of this product during synthesis may be crucial. These findings perhaps indicate that internal surface area alone (measured by BET) may not always necessarily be a reliable indicator of good NO storage/release performance. Dietzel et al. reported a wide range in surface areas measured by nitrogen adsorption depending on how the MOF was pre-treated. ${ }^{14}$ In this present study, Solv-CPO-27(Mg) and 2SRF-CPO-27(Mg) show very different BET surface area measurements (despite being treated equally), yet their NO release (and adsorption) performance are very similar.

At present, gravimetric adsorption/storage data is unavailable for one-step and low temperature samples therefore it is unclear whether the reduction in NO release associated with poorer crystallinity/surface area in the case of CPO-27(Ni) and poorer surface quality in the case of $\mathrm{CPO}-27(\mathrm{Zn})$ is due to lower adsorption and/or storage, or whether less of the stored NO is releasable. The current limited gravimetric data for Solvand $2 \mathrm{SRF}-\mathrm{CPO}-27(\mathrm{Zn})$ and $(\mathrm{Ni})$, combined with their release 


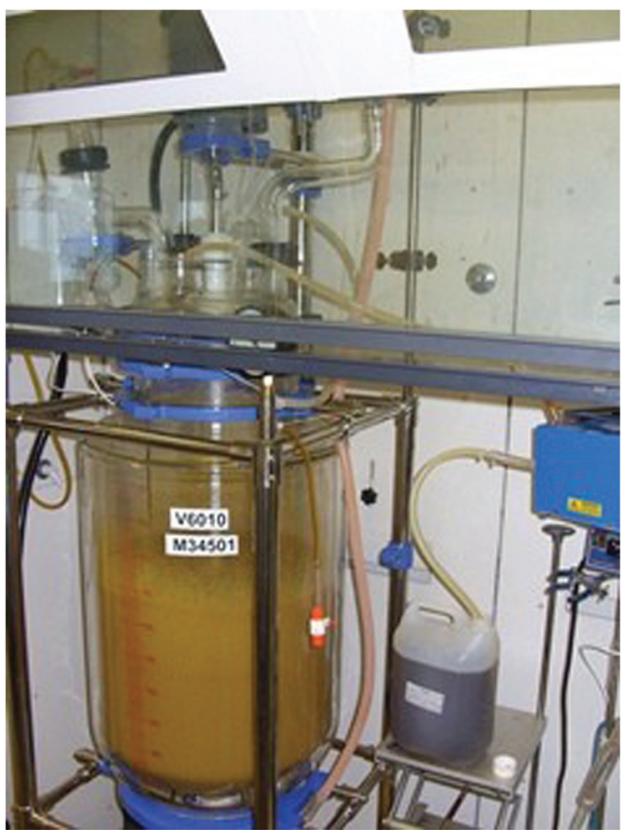

Fig. $11100 \mathrm{~L}$ production of 1SRT-CPO-27(Zn).

data, suggest that the latter case cannot be ruled out. Work is on-going to examine these issues.

\section{Conclusion}

We have shown that MOF materials capable of delivering bioactive levels of NO can be made at scale from water-based low temperature processes. Although the total levels of NO released from the low temperature products are not as high as what could be achieved using solvothermal methods, they are more than adequate for many applications. The results indicate that the processes described above can afford adequate NO adsorption/release performance without recourse to toxic solvents, the requirements to solvent exchange, or the need to activate at very high temperatures. The shorter and less severe synthesis conditions, conducted in an open vessel instead of a sealed autoclave, are much more conducive to transfer to large-scale production. This, in combination with the lower required activation temperature and no requirement for solvent exchange, represents an important step forward in the development of these materials for commercial application. The results also show that NO storage and release performance varies depending on the metal employed, suggesting that these properties could be tuned further by exploring the $\mathrm{Ni}$, $\mathrm{Mg}$ and $\mathrm{Zn}$ composition field, as well as varying the synthesis method.

An interesting conclusion that can also be taken from this research is that the BET surface areas calculated form nitrogen adsorption at $77 \mathrm{~K}$ are not good predictors for the adsorption of gases like NO at room temperature. As such BET surface areas are often used as the standard measurement of porosity, but clearly the situation may not be so simple.

\section{Acknowledgements}

We thank Scottish Enterprise for funding for the scale up work (POC13). We gratefully acknowledge the EPSRC (EP/K025112/1) and the Royal society for the Brian Mercer Award for Innovation (MI120033).

\section{References}

1 C. Janiak and J. K. Vieth, New J. Chem., 2010, 34(11), 2366.

2 P. Silva, S. M. F. Vilela, J. P. C. Tome and F. A. A. Paz, Chem. Soc. Rev., 2015, 44(19), 6774.

3 M. Dincă and J. R. Long, Angew. Chem., Int. Ed., 2008, 47, 6766.

4 R. E. Morris and P. S. Wheatley, Angew. Chem., Int. Ed., 2008, 47, 4966.

5 J. R. Li, R. J. Kuppler and H. C. Zhou, Chem. Soc. Rev., 2009, 38, 1477.

6 A. C. McKinlay, B. Xiao, D. S. Wragg, P. S. Wheatley, I. L. Megson and R. E. Morris, J. Am. Chem. Soc., 2008, 130, 10440.

7 A. Butler and R. Nicholson, Life, Death and Nitric Oxide, The Royal Society of Chemistry, Cambridge, UK, 2003.

8 H. F. Zhu, B. Ka and F. Murad, World J. Surg., 2007, 31, 624.

9 M. R. Miller and I. L. Megson, Br. J. Pharmacol., 2007, 151, 305.

10 D. J. Tranchemontagne, J. R. Hunt and O. M. Yaghi, Tetrahedron, 2008, 64, 8553.

11 S. R. Caskey, A. G. Wong-Foy and A. J. Matzger, J. Am. Chem. Soc., 2008, 130, 10870.

12 P. D. C. Dietzel, V. Besikiotis and R. Blom, J. Mater. Chem., 2009, 19, 7362.

13 P. D. C. Dietzel, B. Panella, M. Hirscher, R. Blom and H. Fjellvåg, Chem. Commun., 2006, 959.

14 P. D. C. Dietzel, R. Blom and H. Fjellvåg, Eur. J. Inorg. Chem., 2008, 23, 3624.

15 A. R. Millward and O. M. Yaghi, J. Am. Chem. Soc., 2005, 127, 17998.

16 J. L. Rowsell and O. M. Yaghi, J. Am. Chem. Soc., 2006, 128, 1304.

17 P. D. C. Dietzel, R. E. Johnsen, R. Blom and H. Fjellvåg, Chem. - Eur. J., 2008, 14, 2389.

18 P. M. Schoenecker, C. G. Carson, H. Jasuja, C. J. J. Flemming and K. S. Walton, Ind. Eng. Chem. Res., 2012, 51(18), 6513.

19 M. J. Duncan, S. J. Warrender, P. S. Wheatley and R. E. Morris, Patent application, WO2013186542A1, 2013.

20 M. Sánchez-Sánchez, N. Getachew, K. Diaz, M. Diaz-Garcia, Y. Chebude and I. Diaz, Green Chem., 2015, 17, 1500. 
21 U. Muller, G. Lippert, O. Schubert, M. Hesse, R. Hesse, M. Stoesser and O. Yaghi, US Pat, 7411081B2, 2004.

22 J. Guasch, P. D. C. Dietzel, P. Collier and N. Acerbi, Microporous Mesoporous Mater., 2015, 203, 238.

23 D. Yu, A. O. Yazaydin, J. R. Lane, P. D. C. Dietzel and R. Q. Snurr, Chem. Sci., 2013, 4, 3544.
24 M. H. Rosnes, M. Opitz, M. Frontzek, W. Lohstroh, J. P. Embs, P. A. Georgiev and P. D. C. Dietzel, J. Mater. Chem. A, 2015, 3, 4827.

25 N. J. Hinks, A. C. McKinlay, B. Xiao, P. S. Wheatley and R. E. Morris, Microporous Mesoporous Mater., 2010, 129, 330 . 